\title{
Correction to: Bias-Based Bullying and School Adjustment among Sexual and Gender Minority Adolescents: The Role of Gay-Straight Alliances
}

\author{
Leah M. Lessard $\mathbb{D}^{1} \cdot$ Ryan J. Watson ${ }^{2} \cdot$ Rebecca M. Puhl ${ }^{1,2}$
}

Published online: 20 April 2020

(c) Springer Science+Business Media, LLC, part of Springer Nature 2020

Correction to: Journal of Youth and Adolescence (2020) https://doi.org/10.1007/s10964-020-01205-1

The original version of the article was inadvertently published with the errors in the table. In Table 2, last row, 2nd column, the value should be $-0.06^{* * *}(0.01)$ instead of $-0.06^{* *}(0.01)$. In the same row, 1 st column, the word should be "alliance" instead of "aliance".

The original article has been corrected.

Publisher's Note Springer Nature remains neutral with regard to jurisdictional claims in published maps and institutional affiliations.

The original article can be found online at https://doi.org/10.1007/ s10964-020-01205-1.

Leah M. Lessard

leah.lessard@uconn.edu

1 Rudd Center for Food Policy \& Obesity, University of

Connecticut, One Constitution Plaza, Suite 600, Hartford, CT

06103, USA

2 Department of Human Development and Family Sciences, University of Connecticut, 348 Mansfield Road, U-1058,

Storrs, CT 06269, USA 